Luciano José Pereira ${ }^{(a)}$

Tatiana Pereira-Cenci ${ }^{(b)}$

Stela Márcia Pereira(c)

Altair Antoninha Del Bel Cury ${ }^{(d)}$

Glaucia Maria Bovi Ambrosano(e)

Antônio Carlos Pereira(e)

Maria Beatriz Duarte Gavião(f)

(a) PhD, Professor, Clinical Dentistry Graduate Program, Oral Diagnosis Area, Vale do Rio Verde University (UNINCOR), Três Corações, MG, Brazil.

(b) PhD, Professor, Department of

Prosthodontics, Federal University of

Pelotas, RS, Brazil.

(c) PhD, Professor, Department of Social Dentistry and Collective Health, Lavras University Center (UNILAVRAS), MG, Brazil.

(d) $\mathrm{PhD}$, Professor, Prosthodontics and Periodontology Department, Piracicaba Dental School, University of Campinas, Piracicaba, SP, Brazil.

(e) $\mathrm{PhD}$, Professor, Social and Public Health Department, Piracicaba Dental School, University of Campinas, Piracicaba, SP, Brazil.

(f) $\mathrm{PhD}$, Professor, Pediatric Dentistry Department, Piracicaba Dental School, University of Campinas, Piracicaba, SP, Brazil.

Corresponding author:

Luciano José Pereira

Rua Horácio de Carvalho, 125

Lavras - MG - Brazil

CEP: 37200-000

E-mail: lucianojosepereira@yahoo.com.br

\section{Psychological factors and the incidence of temporomandibular disorders in early adolescence}

\begin{abstract}
The purpose of the present study was to evaluate the relationship between psychological variables and the clinical diagnosis of temporomandbular disorders (TMD) in 12-year-old adolescents. TMD pain was assessed by RDC/TMD examination (Research Diagnostic Criteria for Temporomandibular Disorders) (Axis I and II). Five-hundred and fifty-eight subjects (330 girls and 228 boys) were examined. Bivariate analyses were performed using the Chi-square test $\left(\chi^{2}\right)$. The logistic regression models were adjusted estimating the Odds Ratios (OR), their $95 \%$ confidence intervals (CI), and significance levels. Only $2.19 \%$ of the boys and $8.18 \%$ of the girls presented one of the Axis I categories. All variables from axis II were related to TMD diagnosis $(\mathrm{p}<0.001)$. Gender was significantly related to TMD diagnosis $(\mathrm{p}=0.0028)$. The risk of TMD incidence for girls was 3.5 times higher than that for boys (Odds Ratio $=3.52$, Confidence Interval 1.31-9.43). The individuals who presented the variable "characteristics of pain intensity" (CPI) higher than 0 had 31 times more risk of TMD incidence (Odds Ratio $=31.361$, Confidence interval 6.01-163.5). We concluded that psychological variables and female gender are important risk indicators related to TMD incidence, even in adolescents.
\end{abstract}

Descriptors: Temporomandibular joint disorders; Adolescent psychology; Pain. 


\section{Introduction}

Temporomandibular disorder (TMD) is a collective term embracing a number of clinical conditions involving the temporomandibular joint (TMJ), masticatory muscles and/or associated structures. ${ }^{1}$ It has generally been presumed to be a condition affecting adults; however, epidemiological studies have reported the presence of signs and symptoms in children..$^{2-7}$ The prevalence is low in young children but increases with age in adolescence up to young adulthood. ${ }^{8}$

Presence of pain elsewhere in the body, female gender and perhaps pre-existing depressive symptoms are associated with the onset and maintenance of temporomandibular pain in adults. ${ }^{9}$ Epidemiologic studies have also found a higher prevalence of these conditions, and back pain as well, ${ }^{10}$ among teenage girls compared to boys. ${ }^{11}$ The fact that some women are more susceptible to musculoskeletal pain than men, even in the early stages of puberty, is still unknown.

Female reproductive hormones are known to be associated with increased risk of TMD pain. ${ }^{12}$ Likewise, pubertal development is more associated with pain than age. As the presence of reproductive hormones increases the risk of developing pain, TMD pain prevalence should increase throughout puberty in girls. ${ }^{11}$ If gender is related to TMD onset, this factor may begin to play a role during the adolescent period.

Biopsychosocial models emphasizing the multifactorial nature of TMD and considering the role of cognitive, social, and biological factors in the aetiology of TMD have also been considered. ${ }^{13,14}$ There is a consensus among researchers and clinicians about the importance of assessing and managing both physical and psychological factors in TMD patients. The most widely studied measurement method for these variables is the Research Diagnostic Criteria (RDC/ TMD), ${ }^{15,16}$ which established a dual diagnosis that recognizes not only the physical conditions (Axis I), including muscle disorders, disc displacements and other types of joint conditions that may contribute to the pain disorder, but also the psychosocial issues (Axis II) that contribute to the suffering, pain behavior, and disability associated to the patient's pain experience, ${ }^{17}$ including self-report measurements of pain, ${ }^{18}$ depression and somatization.

Thus, the aim of the present study was to evaluate the association between gender and psychological variables (RDC/TMD Axis II) and temporomandibular disorder diagnosis (RDC/TMD Axis I) in 12-year-old children.

\section{Material and Methods Ethical aspects}

This study was approved by the Research Ethics Committee of the Piracicaba Dental School, State University of Campinas. An Informed Consent Form containing information about the clinical examination that would be carried out as well as the benefits and possible risks for participants was obtained from parents prior to the survey. The children were also formally informed about the study procedures and assented to participate.

\section{Study sample and data collection procedures}

Public and private schools were selected by the cluster sampling methods from the official records supplied by the Local Department of Education. The estimated number of 12-year-old children in the city of Piracicaba, SP, Brazil is 5,000. Twentyfour schools were randomly chosen to participate in the study from a total of 60 schools. The number of children was projected considering proportionally the schoolchildren registered in private and public schools. The criterion for inclusion was the age of 12 years. One thousand informed consents were distributed and six hundred adolescents were chosen at random from those who returned the informed consent form. Five-hundred and fifty-eight subjects (330 girls and 228 boys) underwent RDC/TMD examination (Research Diagnostic Criteria for Temporomandibular Disorders). ${ }^{15,16}$ Both Axis I and II were performed by one calibrated examiner. Questions regarding sexual behavior were excluded. If the child did not show up at the date of examination, the researchers returned to the school another day. Since the sample was comprised of children, a calibrated examiner was always present in case one of the volunteers had any doubt. Prior to the examination, the dentist par- 
ticipated in the calibration process, which was divided into theoretical discussions on codes and criteria for the study, and practical activities. Subjects meeting the criteria for myofascial pain with or without limited opening (Axis I, Group 1a or 1b disorders) and/or for disc displacement with reduction, without reduction with limited opening or without reduction without limited opening (Axis I, Group 2a, 2b or 2c) or for arthralgia or arthritis (Axis I, Group 3a or $3 b$ ) were considered to have an RDC/TMD pain diagnosis. The exclusion criteria were facial traumatism, neurological or psychiatric disorders, use of dental prosthesis, previous or present orthodontic treatment and other orofacial pain conditions, which could interfere in RDC/TMD diagnosis.

All subjects were submitted to the RDC/TMD Axis II self-report measurements, in portuguese. ${ }^{19}$ These included the Graded Chronic Pain Scale (GCPS) and depression and somatization measurements. The GCPS includes measurements of the characteristics of pain intensity (CPI), pain related interference and number of disability days (disability). CPI is the average of three 0 to 10 numeric rating scales, asking subjects to report on average, worst, and present facial pain levels. Pain interference or disability is the average of three 0 to 10 numeric rating scales, where subjects were asked to report on interference with daily, recreational/social/family and work-related activities.

\section{Statistical analysis}

The prevalence of TMD according to RDC/TMD was calculated for the entire sample. The dependent variable (TMD diagnosis) was dichotomized according to "yes" or "no". Bivariate analyses were performed to test the influence of independent variables (behavioral variables related to RDC Axis II) on dependent variable TMD, using the Chi-square test $\left(\chi^{2}\right)$ at the $5 \%$ significance level. Then multiple logistic regression analysis using the stepwise procedure was performed in order to identify the associated factors for TMD. Only the independent variables that showed significant association (on the univariate analysis) at $\mathrm{p}<0.05$ were selected for the regression analysis in order to eliminate variables that would make little contribution to the model. ${ }^{20}$
The logistic regression models were adjusted estimating the Odds Ratios (OR), their $95 \%$ confidence intervals (CI), and significance levels. All statistical tests were performed using the SAS software (SAS Institute Inc. 9.1, 2003; Cary, NC, USA) at the 5\% significance level.

\section{Results}

The prevalence of TMD pain diagnosis among 12-year-old children according to the RDC/TMD protocol applied in the present study was low. Only $2.19 \%$ of the boys and $8.18 \%$ of the girls presented one of the Axis I categories. The TMD subdiagnosis distribution is shown in Table 1.

Table 2 shows the association between the independent variables and TMD diagnosis as revealed by the bivariate Chi-square test. The bivariate analysis showed that gender was significantly related to TMD diagnosis $(\mathrm{p}=0.0028)$. All variables from Axis II were related to TMD diagnosis ( $<<0.001)$.

The multivariate stepwise logistic regression ( $\mathrm{Ta}-$ ble 3) with "TMD" as dependent variable showed that "gender" and "characteristics of pain intensity" (CPI) were associated factors for temporomandibular disorder diagnosis. The risk of TMD for girls was 3.52 times higher than for boys (Odds Ratio $=3.52$, Confidence Interval 1.31-9.43). Individuals who presented the variable "characteristics

Table 1 - RDC/TMD subdiagnosis distribution in both genders (Total $n=558$; Total TMD = 32).

\begin{tabular}{|c|c|c|c|}
\hline & Boys & Girls & Total \\
\hline la & 2 & 6 & 8 \\
\hline $\mathrm{lb}$ & 0 & 3 & 3 \\
\hline Ila & 0 & 4 & 4 \\
\hline IIc & 0 & 2 & 2 \\
\hline Illa & 0 & 6 & 6 \\
\hline la/lla & 0 & 1 & 1 \\
\hline $\mathrm{lb} / \mathrm{ll} \mathrm{c}$ & 0 & 1 & 1 \\
\hline $\mathrm{la} / \mathrm{Illa}$ & 1 & 3 & 4 \\
\hline Ila/IIla & 0 & 1 & 1 \\
\hline Ilc/Illa & 1 & 0 & 1 \\
\hline IIla/IIlb & 1 & 0 & 1 \\
\hline Total & 5 & 27 & 32 \\
\hline
\end{tabular}


Table 2 - Bivariate analysis regarding associations between TMD and gender, RDC/TMD Axis II variables (dichotomization by the median).

\begin{tabular}{|c|c|c|c|}
\hline \multirow{2}{*}{ Variable } & \multicolumn{2}{|c|}{ TMD } & \multirow{2}{*}{ p-value } \\
\hline & Yes & No & \\
\hline \multicolumn{4}{|l|}{ Gender } \\
\hline Female & $27 \quad(8.18 \%)$ & $303(91.82 \%)$ & \multirow{2}{*}{0.0028} \\
\hline Male & 5 (2.19\%) & $223(97.81 \%)$ & \\
\hline \multicolumn{4}{|c|}{ Chronic Pain Grade Classification (GCPS) } \\
\hline$=0$ & $10 \quad(2.08 \%)$ & 470 (97.92\%) & \multirow{2}{*}{$<0.0001$} \\
\hline$>0$ & $22(28.21 \%)$ & $56(71.79 \%)$ & \\
\hline \multicolumn{4}{|c|}{ Characteristics of Pain Intensity (CPI) } \\
\hline$=0$ & 7 (1.48\%) & 465 (98.52\%) & \multirow{2}{*}{$<0.001$} \\
\hline$>0$ & 25 (29.41\%) & $60(70.59 \%)$ & \\
\hline \multicolumn{4}{|l|}{ Disability } \\
\hline$=0$ & $20 \quad(3.76 \%)$ & $512(96.24 \%)$ & \multirow{2}{*}{$<0.001$} \\
\hline$>0$ & $12(46.15 \%)$ & $14(53.85 \%)$ & \\
\hline \multicolumn{4}{|l|}{ Depression } \\
\hline$\leq 0.35$ & 3 (1.02\%) & 290 (98.98\%) & \multirow{2}{*}{$<0.001$} \\
\hline$>0.35$ & 29 (10.94\%) & $236(89.06 \%)$ & \\
\hline \multicolumn{4}{|l|}{ Somatization } \\
\hline$\leq 0.25$ & 2 (0.72\%) & 274 (99.28\%) & \multirow{2}{*}{$<0.001$} \\
\hline$>0.25$ & 30 (10.64\%) & 252 (89.36\%) & \\
\hline
\end{tabular}

Table 3 - Multivariate stepwise forward proceeding analysis for TMD and independent variables.

\begin{tabular}{c|c|c|c|c|c}
\hline & & TMD - yes & Odds ratio & Odds ratio (CI) & p-level \\
\hline \multirow{2}{*}{ Gender } & Female & $27(8.18)$ & 3.52 & $1.31-9.43$ & 0.011 \\
\cline { 2 - 6 } & Male & $5(2.19 \%)$ & Reference & & \\
\hline \multirow{2}{*}{$\begin{array}{c}\text { Characteristics of } \\
\text { Pain Intensity (CPI) }\end{array}$} & $>0$ & $25(29.41 \%)$ & 31.361 & $6.01-163.5$ & $<0.0001$ \\
\cline { 2 - 6 } & $=0$ & $7(1.48 \%)$ & Reference & & \\
\hline
\end{tabular}

$\mathrm{Cl}$ : Confidence interval. of pain intensity" (CPI) higher than 0 had 31 times more risk of TMD incidence (Odds Ratio $=31.361$, Confidence interval 6.01-163.5).

\section{Discussion}

The purpose of the present study was to evaluate the relationship between RDC/TMD Axis I and II in adolescents. An additional aim was to investigate risk factors for specific TMD subdiagnoses. This, however, was not done because of the small number of young individuals with TMD. The prevalence of TMD in children is expected to be low. In the present research the mean prevalence was around $6 \%$, which is similar $(6.8 \%)$ to that found previously in a sample of 1,996 children with the same age, using RDC/TMD. ${ }^{9}$ Studies have reported that severe disorder at a young age is rare, ${ }^{1}$ corroborating the present results.

In the sample of 558 boys and girls evaluated in the present study, $2.19 \%$ of the boys and $8.18 \%$ of the girls met the RDC/TMD criteria when examined. In the multivariate analysis, gender was an important risk indicator for TMD. The role of gender in pain is extensively discussed in literature, ${ }^{21}$ suggesting that TMD is considered to be 1.5-2 times more prevalent in women than in men, and that $80 \%$ of the patients treated for this disorder are women. ${ }^{22}$ However, the most prominent gender 
differences have been found in women aged 20-40 years, and the lowest among children, adolescents and the elderly. ${ }^{23}$

Axis II RDC questions involving depression and somatization are subscales from the SCL-90. The SCL-90 is designed to be administered to subjects aged $13+$ with at least a $6^{\text {th }}$ grade reading level. In Brazil, however, $6^{\text {th }}$ grade students are 12 years old which could justify its use at this age. Besides, questions regarding sexual behavior were excluded to avoid embarrassment.

The results of the present study demonstrated that all variables in RDC/TMD Axis II were correlated to TMD diagnosis, which was expected. Psychological disturbances are common in patients with signs and symptoms of TMD, even for adolescents $^{3}$, and depressive behavior is commonly associated with chronic pain. Chronic pain severity in RDC/TMD diagnosed patients has demonstrated significant correlation with depression levels. ${ }^{24}$ In this study, higher disability, depression and somatization scores can be important risk indicators of TMD diagnosis, especially CPI. Considering that the diagnosis, assessment and management of TMD must include both physical (e.g. TMJ, occlusion, muscles) and psychological (e.g. personality, affective states, distress) factors, it is suggested that psy-

\section{References}

1. Thilander B, Rubio G, Pena L, de Mayorga C. Prevalence of temporomandibular dysfunction and its association with malocclusion in children and adolescents: an epidemiologic study related to specified stages of dental development. Angle Orthod. 2002 Apr;72(2):146-54.

2. Bonjardim LR, Gaviao MB, Carmagnani FG, Pereira LJ, Castelo PM. Signs and symptoms of temporomandibular joint dysfunction in children with primary dentition. J Clin Pediatr Dent. 2003;28(1):53-8.

3. Bonjardim LR, Gaviao MB, Pereira LJ, Castelo PM. Anxiety and depression in adolescents and their relationship with signs and symptoms of temporomandibular disorders. Int J Prosthodont. 2005 Jul-Aug;18(4):347-52.

4. Kritsineli M, Shim YS. Malocclusion, body posture, and temporomandibular disorder in children with primary and mixed dentition. J Clin Pediatr Dent. 1992 Winter;16(2):86-93.

5. Morinushi T, Ohno H, Ohno K, Oku T, Ogura T. Two year longitudinal study of the fluctuation of clinical signs of TMJ chological measurement can be an effective tool in the current integrated approach with regard to the biopsychosocial model of TMD. The Axis II variables in the present study were dichotomized by the median value, since the sample was comprised of young subjects, and severe psychological alteration is rare. Although the RDC/TMD scales of depression and somatization have considerable data in support of reliability, validity and clinical utility when compared with other measurements of psychological status and psychosocial functioning, ${ }^{16}$ they merely provide an assessment of clinical characteristics and are not a diagnosis. The results could be more significant in individuals with clinically diagnosed TMD, which will be the focus of our future studies.

\section{Conclusion}

Psychological variables and gender are important risk indicators for TMD diagnosis incidence, even in adolescents.

\section{Acknowledgments}

The first author wishes to thank the CNPq (Brazilian Council for Scientific Research and Development, grant \#151940/06-1) for the Postdoctoral scholarship provided for the undertaking of this research. dysfunction in Japanese adolescents. J Clin Pediatr Dent. 1991 Summer;15(4):232-40.

6. Sonmez H, Sari S, Oksak Oray G, Camdeviren H. Prevalence of temporomandibular dysfunction in Turkish children with mixed and permanent dentition. J Oral Rehabil. 2001 Mar;28(3):280-5.

7. Wahlund K. Temporomandibular disorders in adolescents. Epidemiological and methodological studies and a randomized controlled trial. Swed Dent J Suppl. 2003;(164):inside front cover, 2-64.

8. Egermark I, Carlsson GE, Magnusson T. A 20-year longitudinal study of subjective symptoms of temporomandibular disorders from childhood to adulthood. Acta Odontol Scand. $2001 \mathrm{Feb} ; 59(1): 40-8$.

9. LeResche L, Mancl LA, Drangsholt MT, Huang G, Von Korff M. Predictors of onset of facial pain and temporomandibular disorders in early adolescence. Pain. 2007 Jun;129(3):26978. 
10. Wedderkopp N, Andersen LB, Froberg K, Leboeuf-Yde C. Back pain reporting in young girls appears to be pubertyrelated. BMC Musculoskelet Disord. 2005 Nov;1(6):52.

11. LeResche L, Mancl LA, Drangsholt MT, Saunders K, Korff MV. Relationship of pain and symptoms to pubertal development in adolescents. Pain. 2005 Nov;118(1-2):201-9.

12. LeResche L, Saunders K, Von Korff MR, Barlow W, Dworkin SF. Use of exogenous hormones and risk of temporomandibular disorder pain. Pain. 1997;69(1-2):153-60.

13. Sherman JJ, LeResche L, Huggins KH, Mancl LA, Sage JC, Dworkin SF. The relationship of somatization and depression to experimental pain response in women with temporomandibular disorders. Psychosom Med. 2004 Nov-Dec;66(6):85260.

14. Suvinen TI, Reade PC, Kemppainen P, Kononen M, Dworkin SF. Review of aetiological concepts of temporomandibular pain disorders: towards a biopsychosocial model for integration of physical disorder factors with psychological and psychosocial illness impact factors. Eur J Pain. 2005 Dec;9(6):613-33.

15. Dworkin SF, LeResche L. Research diagnostic criteria for temporomandibular disorders: review, criteria, examinations and specifications, critique. J Craniomandib Disord. 1992;6(4):301-55.

16. Dworkin SF, Sherman J, Mancl L, Ohrbach R, LeResche L, Truelove E. Reliability, validity, and clinical utility of the research diagnostic criteria for temporomandibular disorders axis II scales: depression, non-specific physical symptoms and graded chronic pain. J Orofac Pain. 2002;16(3):207-20.

17. Sipilä K, Zitting P, Siira P, Laukkanen P, Jarvelin MR, Oikarinen KS et al. Temporomandibular disorders, occlusion, and neck pain in subjects with facial pain: a case-control study. Cranio. 2002;20(3):158-164.

18. Von Korff M, Ormel J, Keefe FJ, Dworkin SF. Grading the severity of chronic pain. Pain. 1992 Aug;50(2):133-49.

19. Lucena LB, Kosminsky M, Costa LJ, Góes PSA. Validation of the Portuguese version of the RDC/TMD Axis II questionnaire. Braz Oral Res. 2006 Oct-Dec;20(4):312-7.

20. Lucas SD, Portela MC, Mendonça LL. Variations in tooth decay rates among children 5 and 12 years old in Minas Gerais, Brazil. Cad Saude Publica. 2005 Jan-Feb;21(1):55-63.

21. Dao TT, LeResche L. Gender differences in pain. J Orofac Pain. 2000 Summer;14(3):169-84.

22. LeResche L. Epidemiology of temporomandibular disorders: implications for the investigation of etiologic factors. Crit Rev Oral Biol Med. 1997;8(3):291-305.

23. Meisler JG. Chronic pain conditions in women. J Womens Health. 1999 Apr;8(3):313-20.

24. Tesch RS, Denardin OV, Baptista CA, Dias FL. Depression levels in chronic orofacial pain patients: a pilot study. J Oral Rehabil. 2004 Oct;31(10):926-32. 